\title{
The Effectiveness of youth Entrepreneurship Programmes in Enhancing an Entrepreneurial Culture in Swaziland
}

\author{
Sabelo Dlamini, H. Bimha \\ Mancosa Graduate School of Business, 16 Samora Machel St, Durban Central, Durban, South Africa
}

\begin{abstract}
The purpose of the study was to assess the effectiveness of a Swaziland programme in inculcating an entrepreneurial culture among the youth in the wake of high levels of youth unemployment. Opinions and perceptions of tertiary students on the effectiveness of the programme, and their strategies for developing entrepreneurship among youth in Swaziland were gathered in a survey that involved 123 current members in six different institutions of higher learning. Principal literature reviews showed that lack of access to finance was a major barrier to entrepreneurial entry for young people in Swaziland because a number of youth entrepreneurial programmes were designed without the involvement of young people hence not addressing the needs of the youth. Findings from the primary study indicate that tertiary students believe the programme is effective in imparting entrepreneurial knowledge and also believe that entrepreneurship is a credible career path. The same findings however further reveal that the most active students are in their first year of study and the interest in continuing with the programme decreases as they pursue further years of study. This therefore suggests the existence of weaknesses and loopholes in the manner the programme is managed and marketed.
\end{abstract}

Keywords: entrepreneurial programmes; youth development

\section{Introduction}

This research is conducted with the aim to assess the effectiveness of youth entrepreneurship programmes in Swaziland with an emphasis on a particular programme. This programme aims to teach entrepreneurship in tertiary institutions while imparting entrepreneurial and self-help skills to communities. This research looked into the effectiveness of the programme in inculcating an entrepreneurship culture among the youth of the Kingdom of Swaziland.

\subsection{Background to the problem}

The Swaziland Government is financing a number of programmes to enhance entrepreneurship among the youth and fight the scourge of unemployment. These programmes include a Youth Enterprise Fund housed under the Ministry of Sports, Youth and Culture to enable young people to access finance for business start-ups. The government is also financing entrepreneurial programmes in high schools and tertiary institutions to encourage students to take up entrepreneurship activities to create jobs and sustainable livelihoods. In High Schools, the Junior Achievement programme is presented as a practical way of ensuring that students learn the theories of entrepreneurship while practically establishing projects to yield a profit and to teach students on the various aspects of entrepreneurship activity. The other programme which is independent, non-government and the basis of this study is this particular programme which targets tertiary students to ensure they do not just look for employment after graduation but start their own ventures and create employment. The programme stems from an international organisation that was formed in the United States of America in 1975 with a two pronged intention. The first was to inspire tertiary students to venture into entrepreneurship and secondly uplift communities with entrepreneurial projects that raise the standard of living and improve quality of life in those communities. The growing problems driven by unemployment challenges have forced development oriented organisations to develop programmes aimed at assisting governments in tackling the unemployment issue in different ways. The Swaziland programme started as a pilot project in 2002 with the aim of teaching the practicality of entrepreneurship in tertiary institutions. The programme started with only one team from the University of Swaziland, Kwaluseni Campus. It currently has 10 teams taken from seven institutions of higher learning in the Kingdom. This strategic programme is expected to produce a critical segment of the population which is skilled and ready to start sustainable businesses that create employment opportunities for others as opposed to start looking for employment. Despite the introduction of these entrepreneurship programmes, the rate of unemployment among graduates and young people remains high and one wonders if the programmes are effective at all. According to the Swaziland Integrated Labour Force (2013), the national unemployment rate stands at $28 \%$ of which $52 \%$ are persons aged between $15-24$ years. This is regarded to be amongst the highest rates of unemployment in Africa (Brixiova and Kangoye, 2013:2). There has been no study on the impact of this programme in Swaziland hence the purpose of this research is to assess its effectiveness in enhancing an entrepreneurial culture among the youth of the Kingdom. 


\subsection{Problem statement}

Almost $41 \%$ percent of tertiary graduates in the Kingdom of Swaziland are unemployed (United Nations, 2013). This is despite the fact that a number of entrepreneurial programmes targeting the youth have been introduced and sponsored by the Government of Swaziland and the private sector. These programmes include this programme that was introduced at tertiary institutions in 2002 to inculcate a culture of entrepreneurship among students and to ensure that college graduates do not just look for employment after graduation but start business for self-sustenance. Lack of reliable and long term solutions to youth unemployment is a time bomb for further social problems for the country.

\subsection{Research questions}

The following research questions were adopted for the study:

- What are the opinions and perceptions of tertiary students on the effectiveness of the Swaziland programme?

- What factors affect the effectiveness of the Swaziland programme?

- What strategies are employed in implementing the Swaziland programme?

- What recommendations can be made to improve the Swaziland programme's effectiveness?

\subsection{Significance of study}

This research is expected to generate new information which can be of great benefit to the programme's secretariat and tertiary students in determining the impediments to success and ways to achieve their goals. The study can generate information necessary for use by Government and private sponsors to improve the effectiveness of youth entrepreneurial programmes. The research can also make new discoveries that can assist future researchers who may wish to explore further on the impact of this programme in particular, and in youth entrepreneurial programmes in general.

\section{Literature Review}

Entrepreneurship is regarded as a potent tool to fight unemployment especially among the youth. It is regarded by many as the gateway towards self-sustainability, empowerment and economic development (Naude, 2013:4). Literature defines entrepreneurship differently but the one common denomination seems to be the creation of a venture for profit. Kuratko, Morris and Covin (2011:9) defines entrepreneurship as means to create something different and innovative, acquiring and utilisation of resources to implement a differentiated venture, exploiting opportunities to make profit, and taking calculated risks in venturing into untapped territory to create value. Ahmad (2010:205) mentions that risk taking is the one trait that distinguishes entrepreneurs from nonentrepreneurs. Abzari and Safari (2010:5) cite persistence as an important trait for any individual or organisation attempting to achieve change through entrepreneurship. Entrepreneurship is viewed as a vehicle towards enhancing economic dynamism and activity as it remains critical in minimizing unemployment thus reducing the rate of poverty. Naude (2013:4) believes that a number of governments have shifted their attention towards entrepreneurship development to improve the lives of citizens and create a thriving economy. It has become a core development concept in most of the countries that have remarkably reduced poverty and achieved economic success like China (Naude 2013:4). In a study on the link of entrepreneurship and economic development, Naude (2013:13) found that there is a higher level of entrepreneurial activity in low-income countries than in middle income countries. This may imply that there is lack of innovation in developing countries and entrepreneurship tends to be more necessity motivated (Naude, 2013:13). Innovation is a central element of a vibrant and successful entrepreneurial society. Naude (2013:13) found that higher levels of economic growth are in tandem with high levels of innovative forms of entrepreneurship. He noted that entrepreneurship has a positive influence on economic measures of development including gross domestic product (GDP), productivity and employment. For the purposes of this research, the researcher concentrated on necessity driven entrepreneurship as a trait that is prevalent in countries with high unemployment rates like Swaziland as the basis of this study. Developing countries such as Swaziland can by and large be classified to be more driven by necessity towards entrepreneurship development than any other trait.

\subsection{Youth entrepreneurship in Swaziland}

High levels of unemployment across the African continent especially affecting the youth have amplified the need to consider entrepreneurship as a credible career path. Swaziland is not excluded as the government has highlighted the improvement of small and medium enterprises (SME's) among national development priorities with an emphasis on youth entrepreneurship. While there is no general international age classification for youth, the Swaziland National Youth Policy (2009) classifies youth as persons between the ages of 15-35. Ncube, et al. (2013:6) in a study on youth entrepreneurship in Swaziland, identified six constraints to youth entrepreneurship in Swaziland as the following:

DOI: $10.9790 / 7388-0703047382 \quad$ www.iosrjournals.org $\quad 74 \mid$ Page


- The youth is not involved in economic activities in the country.

- Society underestimates the capabilities of young people and they are rarely offered entrepreneurship opportunities.

- Lack of access to capital and information on how to get start-up loans

- The youth lack skills to identify opportunities that can be turned into viable businesses.

- Entrepreneurship programmes seem to be not geared toward uplifting the youth.

- No incubator groups where the youth can meet to generate innovative business ideas.

The effectiveness of any youth entrepreneurship programme in Swaziland can therefore be tested on whether it addresses the impediments that have been articulated above as stumbling block towards youth entrepreneurship.

\subsection{Entrepreneurial intention and attitudes}

The degree of entrepreneurial entry is highly dependent on entrepreneurial intentions that can be classified to incorporate behavior, attitude and social norms. The success of the efforts to stimulate and support new generations of entrepreneurs isdependent on identifying and reducing the barriers to entrepreneurial intention (Herrington, Kew and Kew 2015:23). Rideout and Grey (2013:331) cite the popular theory of planned behaviour of Ajzen's (1991) that ascertains that "entrepreneurial intentions influence entrepreneurial behavior." The theory contends that entrepreneurial education and experience can shape entrepreneurial intentions. The theory of planned behaviour in essence argues that that an individuals' intentions determine whether he/she will venture into an entrepreneurial venture or not. The theory of planned behavior features prominently in a number of studies of entrepreneurial intention. The theory claims that attitude, social norm, and controlled behavior predict intention of an action (Zhang, Wang and Owen 2015:62). Malebana and Swanepoel (2014:3) cite a number of factors that persuade an individual's intention to explore an entrepreneurial venture. These include an individual's belief and conviction in their abilities to perform a particular function coupled with the amount of support an individual perceives will be received from peers and community of business. Rauch and Hulsink (2015:190) support the notion and interpret social norms as more than just social but subjective norms in that they are based on complying with beliefs of family and friends in whether venturing into a particular business will yield the expected results. These norms restrict the potential entrepreneur to a space where they highly value the opinions of others, especially close friends and family. Singh, Verma and Rao (2016:39) cite innovativeness as another important trait that influences entrepreneurial intention and is an important element of entrepreneurship. The capacity to be creative and to constantly embrace new ideas and new ways of executing different projects independently is an entrepreneurial trait that boosts intentions (Singh, et al., 2016:39).

\subsection{Entrepreneurial culture}

Entrepreneurial culture is regarded as a major component that differentiates the level of economic success for countries (Brownson, 2013:146).In some cultures, people are highly motivated to be unique, whereas in others, people prefer to be like everyone else (Urban, 2007:87). Autio, Pathak and Wennberg (2013:2) notes that individualistic cultures tend to attract more people into business as it is closely related with entrepreneurs who are more willing to take risks. Risk averse cultures tend to minimize chances of entry into entrepreneurship. On the other hand collectivist countries usually have a culture of entrepreneurship that views business growth as their societal responsibility where the collective benefit precedes individual benefit (Autio, et al., 2013:2). The advantage of collectivism is that while individualistic countries tend to have many entrepreneurs, collectivist countries create more jobs as they do not necessary aim at creating many entrepreneurs but instead concentrate on the number of jobs (Autio, et al., 2013:2). Kuratko, et al. (2011:281) identifies advantages and disadvantages of individualism versus collectivism. Individualism is consistent with achievement motivation and a greater number of novel concepts, ideas and breakthrough innovations while in collectivism cultures the need for collective consensus and community support in venturing into business is regarded as important. On the negative side, individualist entrepreneurs are labelled as selfish in that they are more concerned about themselves than the overall good of others while collectivism entrepreneurs waste a lot of time trying to reach consensus thus letting go of promising opportunities (Kuratko, et al., 2011:281). Pinillos and Reyes (2011 cited in Hayton and Cacciotti 2013:713) question the notion of a simple linearassociation between culture and entrepreneurial activity. Their argument disputes the common view that individualism is positively associated with entrepreneurship. They observed that there are many countries characterized by collectivist orientation which also exhibit high levels of entrepreneurial activity. Wennberg, Pathak and Autio(2013:757) support this view and in their study found that propensity to start a business is more prevalent in cultures that prefer institutional collectivism. Their study also disputed the notion that fear of failure is a common thread among collectivism cultures. Theories of entrepreneurial entry suggest that "individuals consider not only their own ability to succeed and the possibility of failure, but also how this action is consistent 
with prevailing cultural norms and practices" (Wennberg, et al., 2013: 758). It is apparent that more research still needs to be pursued in determining the cultural characteristics prominent in societies with a high degree of entrepreneurial activity. For the purposes of the study the researcher is leaning towards the differences between individualistic and collectivism cultures identified by Kuratko, et al. (2011:281) in view of the obtaining situation in Swaziland where the entrepreneurial culture can arguably be classified under collectivism. The question to address for the researcher was whether the collectivism culture may negatively influence graduates' intentions to venture into business even with the knowledge gained from entrepreneurial education. A culture of uncertainty avoidance is without doubt a negative influence on chances of entrepreneurial entry mainly because it is related to risk avoidance. It can be deduced from the reviewed literature that culture affects self-efficacy and fear of failure even though conflict of opinions persist on whether chances of venturing into business are more minimal for citizens of countries that exhibit traits of institutional collectivism.

\subsection{Entrepreneurial education}

The last decade has seen an increasing number of government and private sector sponsored programmes aimed at promoting youth entrepreneurship across the world to fight the scourge of unemployment. These programmes differ in design, ranging from providing a seed capital for business start-ups to introduction of entrepreneurial education programmes or combining the two (Raunch and Hulsink, 2015:187).Institutions around the world such as governments, non-governmental organisations, multilateral and bilateral development partners promote youth entrepreneurship programmes focusing on entrepreneurial education to address spiralling youth unemployment and support economic prosperity (Nadgrodkiewisz, Nakagaki, Bueger, Citrome andBrister2013:7). There remains an age old debate on whether entrepreneurship can be taught or it is something one is born with. Literature varies to a certain degree on this subject but seems to conclude that it can be taught though the differences remain on how it can be taught. Fatoki and Oni (2014:587) believe there needs to be a proper match between teaching skills and techniques and the needs of students for entrepreneurial education to be effective. Effective entrepreneurship education "manifests itself in creative strategies, innovative tactics, uncanny perception of trends and market mood changes, courageous leadership when the way forward is not obvious." (Fatoki and Oni, 2014:587). The argument therefore of whether entrepreneurship is something learnt or one is born with is nullified by interventions such as entrepreneurial education which aims to impart entrepreneurial knowledge and skills to both students and adults who are looking at self-sustainability than be absorbed by the labour market. In assessing the effectiveness of the programme in Swaziland, it was important for the researcher to ascertain whether the above mentioned criteria is incorporated into the programme.

\subsection{Entrepreneurship education in Swaziland}

The extent of entrepreneurship education in Swaziland is not well captured in literature amplifying the need for more research on this subject. This could be attributed to that entrepreneurship education in schools and tertiary institutions is a relatively new phenomenon which is still taking ground with the introduction of the Junior Achievement programme in high schools and this programme in tertiary institutions. A majority of young Swazis are neither aware of the processes involved in starting a business nor are they informed on processes of raising capital and obtaining loans to venture into business (United Nations, 2013). This is where entrepreneurial education becomes vital to address these gaps and bring more young people into entrepreneurship with the required knowledge and skills. Ncube, et al. (2013:4) in a study on youth entrepreneurship in Swaziland noted that most educational programmes in entrepreneurship are not targeted at young people. As a result 41 percent of graduates from tertiary institutions in the Kingdom are unemployed and have no entrepreneurial knowledge as a buffer towards self-employment (United Nations, 2013:7). To address the challenge, some tertiary institutions in the Kingdom have since introduced entrepreneurship educational programmes. This includes the University of Swaziland (UNISWA) Luyengo campus which in 2008 started an entrepreneurial course for first year students and an entrepreneurial project for the second year and third year students (Mantyi-Ncube and Dlamini, 2014:602).

\section{Research Methodology}

Research philosophy can be classified into two major approaches, namely positivist and phenomenological research. The positivist, which is generally referred to as the quantitative type of research and the phenomenological, otherwise referred to as the qualitative or interpretivist research (Cooper and Schindler, 2010:218)

\subsection{Quantitative (Positivist) research}

Quantitative research involves the use of numerical measurement and statistical analysis of measurements to examine social phenomena (Saunders, Lewisand Thornhill 2009:139). It interprets reality as a phenomena that can be observed and measured. Its main advantage is that it is highly objective and reliable in 
its findings while encouraging replication (Bryman and Bell, 2007:54). However when applied to business research, its validity is low as not all social phenomena can be accurately and reliably measured (Saunders et al., 2009:139). Quantitative designs involve gathering of data from a sample of the population, usually using survey questionnaires and the results thereof are analyzed statistically using scientific methods, such as the Statistical Programme for Social sciences - SPSS. According to Creswell (2009:164), quantitative research aims at determining the relationship between an independent variable and a dependent variable in a population. Quantitative research designs are either descriptive, that is subjects are usually measured once, or experimental where subjects are measured before and after a treatment. A descriptive study establishes only associations between variables. An experiment establishes causality. In this study: effectiveness of the programme in Swaziland, it was necessary to back-up, with quantifiable statistics, the perceptions of students on various aspects of the programme. The quantitative research method was used in the sense that the analysis of results are based on responses from questionnaire instruments, are numerically oriented, using a deductive approach. The researcher used the computer software programme SPSS for this research because of its compatibility with a structured questionnaire that has close-ended questions. The major difference between quantitative and qualitative research is that quantitative research questions are generally developed before the study begins while qualitative questions are developed at the beginning of the study or as the study continues (Venkatesh, Brown and Sullivan 2016:441). The quantitative method was preferred for this research to minimize subjectivity. Williams (2007:69) articulates that quantitative research is objective in comparison to qualitative method. Another advantage of the quantitative approach identified by Creswell (2009:164) is that it does not only describe behaviours and attitudes of the respondents but also provides hard data on the numbers of people exhibiting those behaviours and attitudes.

\subsection{Positivist research strategy}

Surveys: This is a positivist research design in which a sample is selected from a population and studied to make inferences about the population. It is a popular and common strategy in business and management research and is most frequently used to answer who, what, where, how much and how many questions (Saunders,et al., 2009:144).Surveys typically uses questionnaires and interviews in order to determine the opinions, attitudes, preferences and perceptions of persons of interest to the researcher. It is used for exploratory and descriptive research and allows the collection of a large amount of data from a sizeable population in a highly economical way, often using a questionnaire (Saunders, et al., 2009:144).In well-designed surveys, it is possible to use statistical techniques to assess the applicability and generalisability of the findings to the larger population. Survey strategy allows quantitative data to be collected and analysed using descriptive and inferential statistics, and possible reasons for particular relationships between variables can be suggested (Saunders,et al., 2009:144).

\subsection{Target population}

According to Fricker (2010:2) a target population is the group of elements "to which the researcher wants to make an inference." In this study, the target population is all the active members across 10 faculties of the 7 member tertiary institutions. The active members were chosen for this study as they would be in a position to respond to questions relating to the effectiveness of the programme and give the researcher insight on how the programme impacts on its participants. This group was also chosen for its accessibility as most members were located in the various campuses of the participating institutions.

\subsection{Sampling Strategy}

According to Williams (2007:65), a sample is a subgroup of the population that is selected to participate in the research. While surveying the entire population would be ideal and called a census it may be too expensive to field and analyse hence a sample of the population is preferred to gather information that is representative of the population (Research Lifeline, 2012:2). For the purposes of this study, convenience sampling was used to collect primary data. The researcher used this sampling technique because it is fast, inexpensive, easy and the subjects were readily available in each institution to participate in the study.

\subsection{Research instrument}

To meet the research objectives of the study, the researcher used a closed questionnaire that covered the objectives of the study. The objectives of the study were to gather opinions and perceptions of tertiary students on the effectiveness of the Swaziland entrepreneurship programme, examine the effectiveness of the programme, identify strategies employed in developing entrepreneurship among youth in Swaziland and make recommendations on how the Swaziland Programme can be improved. 
3.6 Pilot study

A pilot study was conducted for this research in line with the advice of Bisits (2014:2) who is against using a questionnaire to collect information from respondents without first testing.

\subsection{Data analysis}

Data was collected from 107 active students and analysed. It was captured and analysed using the Statistical Package for Social Science (SPSS). The researcher made sure to analyse the data and collate the findings with other secondary sources of data in order to ensure validity of findings so as to prevent misinterpreting the multitude of tables and figures.

\subsection{Limitations of study}

Limitations of this research were that it did not include graduates who had passed through the programme. This was mainly because there was no up-to-date database on their current location combined with limited resources and time constraints. This however did not affect the achievement of the objectives of the study as it primarily focused on active members. The best informants in meeting the objectives were therefore the active students.

\subsection{Ethical considerations}

The researcher ensured that none of the collected information was leaked to unwarranted hands in accordance to Resnik (2015) who says a high ethical standard must be upheld when collecting data and measures must be taken to protect the participants involved as any lapses can be significantly harmful. Information collected in this research was treated with strict confidentiality and the identity of participants protected. The questionnaire did not require participants to indicate their names for identification and the returned questionnaires were kept safely out of probing eyes. Secondly, the nature of the study was explained to all participants through the use of an introductory letter. Participation was completely voluntary and no one was coerced into participation nor were they provided with inaccurate information pertaining the study. Resnik (2015) highlights the crucial ethical considerations that were taken into full consideration by the researcher throughout the study:

Avoid anything that would cause physical or emotional harm: There was nothing in the study in the study that could pose danger to the participants. Participation was limited to responding to a questionnaire and not any other task that could endanger the lives of participants. Questions were formulated in a manner that was not harmful to the respondents.

Seek permission: Permission was sought from the programme's secretariat in Swaziland to conduct the study and from the respondents to participate in the study. For the respondents, this was done in form of a covering letter which explained the purpose of the study and sought their consent as it was voluntary.

Objectivity vs. subjectivity: The researcher avoided infusing his own personal biases in determining the findings of the study and instead used the SPSS software to generate results.

\section{Results}

123 active students in 6 institutions of higher learning in the Kingdom of Swaziland participated, 107 responded resulting in a response rate of $87 \% .42 .99 \%$ of the respondents are between 25 to 30 years of age and a further $37.38 \%$ of the respondents between 20 and 24 years of age. Students tend to delay obtaining a tertiary education considering that the average high school completion age in Swaziland is 18 years. It was not the focus of this study to establish reasons why the majority students get to college in their late twenties but it gives an impression that most students start on their careers rather late in life. Male students constitute majority and are represented by $56.07 \%$. The proportion of females is however quite significant at $43.93 \%$ considering the patriarchal nature of the Swazi society. The traditional view has not been supportive of economic emancipation of women. Participation by such a significant number of female students shows a paradigm shift in regard to women participation in business. National competitions like Women Entrepreneur of the Year Awards further serve to reverse the marginalisation of women in the entrepreneurial arena. The majority of the students come from families which do not own a business $-56.07 \%$ of respondents. The fact that one's family owns a business or not, does not seem to have a bearing on the entrepreneurial intention of the students. When comparing responses of students on whether they would consider entrepreneurship as a credible career path against family business ownership, the data reveals that those who do not have family businesses equally want to pursue entrepreneurial career paths as much as those that have family businesses. The data shows that the majority of respondents have been active members for a relatively short period of time (less than 1 year) as represented by $58.9 \%$ of respondents. The distribution further points to fact that the programme is gaining popularity among the students as newer members are more than older ones. A cumulative total of $93.7 \%$ students agree that the 
programme has been highly effective in imparting entrepreneurial skills. A closer look at the data shows that those students who have been members for longer periods seem to hold slightly different views about the impact of the programme compared to those who have been active members for shorter periods. The views of students regarding the financial burden of membership are very divergent. A cumulative $43.92 \%$ agree that membership imposes a financial burden while a cumulative $41.12 \%$ disagree. The remaining $14.95 \%$ are neutral. The majority of students consider entrepreneurship as a credible career path as represented by a cumulative $91.59 \%$ of the respondents. This constitutes an overwhelming majority of the students. A further analysis shows that the views are evenly split across the gender divide. In view of the high youth unemployment levels in Swaziland, such a high level of entrepreneurial intention is positive to the country's aspirations for entrepreneurial development and employment creation. Both female and male students strongly consider entrepreneurship as a credible career path. A cumulative $97.2 \%$ of the students view entrepreneurial education as effective in enhancing intention to engage in business. This view by the students negates the argument of whether entrepreneurship is something one is born with. Such perceptions by students encourage them to seek more entrepreneurial education as a means to increase intention to engage in business rather than resign to fate by believing that entrepreneurship is something one is born with. The majority of the students (cumulative $72.9 \%$ ) rate access to finance as a major barrier to starting a business. The majority of students view family background in business as advantageous in starting a business as represented by a cumulative $58 \%$ of respondents. The students' views are shared by several scholars. Several studies point to family business background as having a bearing on entrepreneurial intention. The majority of those who view family background in business as having a bearing on starting a business come from families who do not own a business. The data shows that the majority of the students do not consider the approval of family and friends as very important in starting a business cumulative $66.4 \%$ who disagree. These findings are contrary to literature findings which attach great importance to family approval to entrepreneurial intention. The views expressed by the students can be interpreted in two ways, firstly at face value that truly the students do not care about getting family approval or secondly that students did not want to give an impression of being dependent on family now that they are at a tertiary institution and perceived to be mature and independent. The majority of the students confirm that the programme has enhanced their entrepreneurial knowledge as shown by a cumulative $87.8 \%$ of students who agree (49.5\% strongly so) that their entrepreneurial knowledge has been enhanced. Less than $4 \%$ cumulatively disagree with notion that the programme has enhanced their skill. These findings are a vote of confidence by the students on the effect of the programme on their entrepreneurial knowledge. The majority of students (cumulative 53.3\%) agree that the programme has an effective mentorship programme post-graduation. A significant proportion of students $(33.6 \%)$ responded that they did not know whether there is an effective postgraduation mentorship programme. The responses by the students who professed ignorance mirrors the fact that most of the students would probably base their views on hearsay rather than experience as none of them have graduated to experience first-hand the post-graduation mentorship programme. The effectiveness of the postgraduation mentorship programme is inconclusive but it remains undisputed that an effective youth entrepreneurship programme should not just limit itself to business knowledge but also provide information on sources of finance coupled with a mentoring programme that helps guide young entrepreneurs as they venture in the world of business. The majority of the students agree that the programme has equipped them with necessary business related skills to start a business after graduation as represented by a cumulative $79.4 \%$ of the students.

This shows that the programme is offering students practical skills that can be applied in the real world of business rather than theoretical knowledge. The programme is doing well in terms of providing students with information on the avenues to access start-up finance. This shows that the programme has a relevant approach in equipping students for the real world of business. The programme seems to be achieving the goal of equipping students with the necessary information to enable them to "hit the ground running" soon after graduation. An overwhelming majority (cumulative 95.3\%) feel motivated to start an entrepreneurial venture after graduation. The high level of motivation holds promise for the country as most students who pass through the programme are bound to start businesses after graduation. The Swaziland programme has enabled the majority of students to create adequate networks and contacts that would help students start a business. Such a high affirmative rating reflects well on the programme considering that $59 \%$ of the respondents have been active members for less than a year. This shows that the programme has strong business skills orientation from very early stages of membership. Networking is critical for students as it gives them the opportunity to mingle with businessman, government officials, financiers and other individuals with information, knowhow and experience that will enable students to avoid unnecessary pitfalls. The programme has been rated as effective in boosting students' confidence and reducing their fear of failure in business. Risk-taking sticks out more frequently in entrepreneurship literature as a core entrepreneurship characteristic. Risk taking propensity and ambiguity tolerance are vital psychological dimensions of entrepreneurship. The programme has proved to be highly effective in effecting attitude changes in keeping with what scholars prescribe as ideal for entrepreneurship education. 


\section{Conclusions And Recommendations}

The analysed data shows that a majority of the programme members learnt about the programme from their peers and other channels and only a few from the secretariat. It can also be noted that a majority of active members are first year students and membership decreases as students pursue further years of their study suggesting the programme is more popular among students in lower classes. However the data shows that students rate the programme highly and are happy with the skills imparted to them through participation in the programme activities. They view membership as prestigious. While a majority opine that the programme has given them information about avenues to access finance, they remain concerned about the reality of accessing finance to start business ventures. There is a concern raised by a sizeable number of students that the programme comes with a financial burden to members and that the time allocated for activities is insufficient.

\subsection{Conclusions}

A number of conclusions can be reached from the findings of the study in congruent with the objectives of this research.

These are:

- The study can conclude that the Swaziland programme is highly rated by students in as far as its effectiveness in imparting entrepreneurial knowledge such as financial, marketing and operations skills leading to most of them viewing entrepreneurship as a credible career path, but the programme does not network the students with potential financiers such as banks.

- The students feel the programme imposes a financial burden and the time allocated for activities is not sufficient. The study concludes that most students are prepared to venture into business after graduation and they agree that the Swaziland programme has provided them with the necessary skills which can get them started as soon as they graduate, and a majority of students are confident enough to launch businesses without fear of failure having undergone the programme.

- The study concludes that one of the factors that impact on the effectiveness of the Swaziland programme is the organisation's inability to link students with potential financiers.

- The programme's membership distribution is concentrated on students pursuing commercial programmes yet students from other disciplines can also become good entrepreneurs if given proper mentorship. The fact that most students got to know about the programme through other means other than the secretariat testifies that the secretariat has failed to make the programme visible to all tertiary students and the declining of membership among senior students shows the organisation has a weak and poor client retention strategy.

\subsection{Recommendations}

Based on the above findings and conclusions it is recommended that:

- The programme should ensure that the entrepreneurial knowledge it imparts to the students gives them exposure to the real world of entrepreneurship. One of the strategies is to make the students understudy successful entrepreneurs. Another strategy would be to sponsor gatherings that attract entrepreneurs like golf tournaments and corporate dinners where the students will participate and network with real time entrepreneurs. It is evident that having all the relevant skills without capital will not help the prospective entrepreneurs' efforts to engage in business, they need real money. The unit should therefore offer its programmes to companies that will give loans to its graduates after the programme.

- The programme should find innovative ways to lessen the financial burden imposed on individual students by being active members of the programme. This can be done through intensification of fund raising strategies. One of the strategies to increase fundraising is to seek corporate sponsorship to host fundraising dinners, galas, concerts, sports events, raffle tickets and more.

- The programme should ensure that enough time is allocated for activities. One strategy is to partner with tertiary institutions and offer a joint programme wherein students received certificates which are officially recognised by relevant bodies such as Ministry of Education and Training. This will also dispel the feelings by students that the programme affects their core study.

- The secretariat should ensure that students get started on a long term entrepreneurship career path while they are still in college rather than wait for them to venture into business post-graduation, and serve as an incubation service for the businesses that the students want to start. The strategy is to ensure that the mentorship programme starts while the students are still in college.

- The programme should link with other business organisations such as the Chamber of Commerce, Global Business Round Table, Federation of Swaziland Employers to further boost confidence and inspire students to venture into business as such meetings or interactions allow students to experience first-hand the challenges faced by successful entrepreneurs. As a strategy, the secretariat should arrange participation of 
teams on forums like the Swaziland International Trade Fair, Entrepreneurship Expo so as to give students real life exposure.

- The programme should ride on the knowledge that membership is considered prestigious by students to recruit more students. They should produce ornaments that further enhance this status like badges of honour and any such material that can be worn during occasions so that they become visible. Another strategy is to profile the students in media programmes including television, radio and print media articles as this serves to not only enhance the status of the programme but increase visibility. One of the strategies is to actively participate in student friendly media and social networks like Facebook, Twitter, Instagram, Whatsapp. The secretariat should also distribute branded regalia such as t-shirts, caps, pens, cups, as a marketing strategy that will boost visibility.

- The secretariat should monitor and evaluate the programme to measure its impact and effectiveness on the move and more frequently. One of the strategies is to commission an independent study every three years to ensure that the delivery of the programme matches up to the intentions and expectations.

\subsection{Further research}

Future research is necessary as the dynamics of youth entrepreneurship continue to evolve. Further research on the effectiveness of youth entrepreneurship education in Swaziland, or lack thereof, may be explored. The emphasis should be on the effects of entrepreneurship education in institutions of higher learning. Literature on this subject is very thin yet more graduates are being churned out every year to face unemployment and escalate the scourge of poverty.

\section{Conclusion}

The findings, conclusions and recommendations in this study indicate that the programme in Swaziland is on the right path in enhancing an entrepreneurial culture that will produce entrepreneurs but needs to implement some changes to enhance its effectiveness. This will ensure that students are well equipped to have successful businesses pre and post-graduation.

\section{References}

[1]. Brixiová, Z., and Kangoye, T. (2013). Youth Employment in Africa: New Evidence and Policies from Swaziland. IZA Discussion Paper No. 7467. Institute for the Study of Labor. Bonn, Germany.

[2]. United Nations (2013). Opportunities and constraints to youth entrepreneurship. A perspective of young entrepreneurs in Swaziland. Report 2013. United Nations Country Team, Mbabane, Swaziland.

[3]. Naude, W. (2013). Entrepreneurship and Economic Development. Theory, Evidence and Policy. Discussion Paper Series, IZA DP number 7507. Institute for the Study of Labor. Bonn, Germany.

[4]. Kuratko, D., Morris, M. and Covin, J. (2011). Corporate Innovation \& Entrepreneurship. $3^{\text {rd }}$ edition, South-Western Cengage Learning, International Edition, Canada.

[5]. Ahmad, M. (2010). Personality traits among entrepreneurial and professional CEO's in SME's. International Journal of Business and Management. Department of Management Sciences, Bahria University, Islamabad, Pakistan. Vol. 5, No. 9, pp. $203-213$.

[6]. Abzari, M., and Safari, A. (2010). The role of culture on entrepreneurship development. A case study: Department of Management, University of Isfahan, Iran.

[7]. Swaziland Government (2009). Swaziland National Youth Policy. Ministry of Sports, Culture and Youth Affairs. Government of the Kingdom of Swaziland printers.

[8]. Herrington, M., Kew J.\& Kew P.(2015).GEM South Africa 2014 Report. Available from: http://www.gemconsortium.org/report.[Accessed on 22 March 2016)].

[9]. Rideout, E., and Grey, D. (2013). Does entrepreneurship education really work? A review and methodological critique of the empirical literature on the effects of University based education. Journal of Small Business Management 2013 51(3), pp. 329-351.

[10]. Ajzen, I. (1991). The theory of planned behavior. Organizational Behavior and Human Decision Processes, 50(2), $179-211$.

[11]. Zhang, P., Wang, C., Owen, C. (2015). A study of entrepreneurial intention of university students. Entrepreneurship Research Journal 2015; 5(1): pp:61-82. De Gruyter.

[12]. Malebana, M.J., Swanepoel, E. (2014). The relationship between exposure to entrepreneurship education and entrepreneurial selfefficacy. Southern African Business Review, Volume 18 Number 1, University of South Africa, Pretoria.

[13]. Rauch, A., Hulsink, W. (2015). Putting entrepreneurship education where the intention to act lies. An investigation into the impact of entrepreneurship education on entrepreneurial behavior. Academy of management learning and education, 2015, Vol. 14, No. 2, pp. 187-204.

[14]. Singh, B., Verma, P., Rao, M. (2016). Influence of individual and socio-cultural factors on entrepreneurial intention. South Asian Journal of Management, India. Volume 23, pp.20-32.

[15]. Brownson, C. D. (2013). Fostering an entrepreneurial culture. A conceptualization. European Journal of Business and Management, Vol.5, No.31, pp. 146-155.

[16]. Urban, B (2007). A framework for understanding the role of culture on entrepreneurship. Pp. 82-95, Department of Management, University of Johannesburg, South Africa.

[17]. Autio, E., Pathak, S., \&Wennberg, K. (2013). Consequences of cultural practices for entrepreneurial behaviors. Journal of International Business Studies, 44(4): pp. 334-362.

[18]. Pinillos, M., Reyes, L (2011). Relationship Between Individualist-Collectivist Culture and Entrepreneurial Activity: Evidence from Global Entrepreneurship Monitor Data. Small Business Economics 37: pp 23-37.

[19]. Hayton, J. and Cacciotti, G. (2013). Is there an entrepreneurial culture? A review of empirical research. Entrepreneurship \& Regional Development. Vol. 25, Nos. 9-10, pp. 708-731. Routledge, Taylor \& Francis group. 
[20]. Wennberg, K., Pathak, S. andAutio, E. (2013). How culture moulds the effects of self-efficacy and fear of failure on entrepreneurship. Entrepreneurship and Regional development. Vol. 25, Nos. 9-10, pp. 756-780. October 2013. Routledge, Taylor and Francis Group.

[21]. Nadgrodkiewics, A., Nakagaki, M., Bueger, C., Citrome, L. andBrister, M. (2013). Guide to youth entrepreneurship programmes for Chambers of Commerce and Business Associations. National Endowment for Democracy. Centre for International Private Enterprise, Washington DC, USA.

[22]. Fatoki, O. and Oni, O. (2014). Students' Perception of the Effectiveness of Entrepreneurship Education at a South African University. Mediterranean Journal of Social Sciences, Volume 5, No. 20, pp. 585-591.

[23]. Mantyi-Ncube, B. andDlamini, N. (2014). The impact of entrepreneurship education and training on entrepreneurial intentions of Consumer Sciences' graduates of UNISWA. International Journal of Current Research. Vol. 6, Issue, 04, pp.621-627, April.

[24]. Cooper, D., Schindler, P. (2010).Business Research Methods. Eleventh edition. McGraw-Hill Education, London.

[25]. Saunders, M., Lewis, P. andThornhill, A. (2009). Research methods for business students, 5th edition, Harlow, Pearson Education.

[26]. Bryman, A. and Bell, E. (2007). Business Research Methods, Second edition. Oxford: Oxford University Press.

[27]. Creswell, J. (2009). Research design. Qualitative, quantitative and mixed method approaches. Third edition. Sage Publications. Inc, Los Angeles.

[28]. Venkatesh, V., Brown, S. and Sullivan, Y. (2016) Journal of the Association for Information Systems. Vol. 17 Issue 7, pp.435-495. $61 \mathrm{p}$.

[29]. Williams, C. (2007). Research methods. Journal of business and economic research, Grand Canyon University, USA. Volume 5, Number 3, pp. 65-72.

[30]. Fricker, R. (2010). Target populations, Sampling Frames and Coverage Error. Naval Postgraduate School, Monterey, California. Available from: http://faculty.np s.edu/rdfricke/MCOTEA_Docs/Lecture/Target/Populations/Sampling/Frames/ and/Coverage/Error.pdf. [Accessed 27 July 2016].

[31]. Research Lifeline (2012). Five steps in creating a sampling survey plan. Available from: http://cdn2.hubspot.net/hub/58820/docs/rl_process_wp_five_step_sampling.pdf[Accessed on 23 July 2016].

[32]. Bisits, P. (2014). How to pretest and pilot a survey questionnaire. Available from: http://www.tools4dev.org/resources/how-topretest-and-pilot-a-surveyquestionnaire/. [Accessed on 22 March 2016].

[33]. Resnik, D. (2015). What is Ethics in Research \& Why is it Important? Available from: http://www.niehs.nih.gov/research/resources/bioethics/whatis.[Accessed 19 March 2016]. 